\title{
Structure-Based Virtual Screening and Molecular Dynamics of Quercetin and Its Natural Derivatives as Potent Oxidative Stress Modulators in ROS-induced Cancer
}

\author{
Abd. Kakhar Umar ${ }^{1, *}$, James H. Zothantluanga ${ }^{2}$ \\ ${ }^{1}$ Department of Pharmacy, Faculty of Math and Natural Sciences, Universitas Tadulako, Palu \\ 94148, Indonesia \\ ${ }^{2}$ Department of Pharmaceutical Sciences, Faculty of Science and Engineering, Dibrugarh \\ University, Dibrugarh 786004, Assam, India
}

Submitted : 29 July 2021, Revised : 12 August 2021, Accepted : 13 August 2021, Published : 20 August 2021

\begin{abstract}
Quercetin derivatives are known to have significant anticancer activity. The activity is strongly influenced by the type and position of the substituent group. By studying the structural pattern of quercetin and its impact on their binding affinity, the development of quercetin-based drugs can be optimized. The study aimed to determine the impact of 3D structure, type, and position of quercetin moiety on its activity against ROS-modulating enzymes that play a role in the induction and growth of ROS-induced cancer. The 23 natural quercetin derivatives were docked to 7 ROS-modulating enzymes using Autodock Vina to determine their binding affinity and interaction. The interaction stability was further studied through molecular dynamics simulation using the CABS Flex 2.0 server. Determination of crucial amino acid targets of the quercetin group was determined using DockFlin. Finally, the toxicity of each test ligand was determined using the pkCSM server. The highest binding affinity for SOD and NOX was produced by quercetin 3'glucoside with the binding energy of -10.2 and $-12.8 \mathrm{kcal} / \mathrm{mol}$. Quercetin 3,4'diglucoside had the highest binding affinity for CAT and GR at -11.5 and -10.5 $\mathrm{kcal} / \mathrm{mol}$, respectively. Routine produced the highest binding affinity at LOX (10.9). Quercetin 3-O-xyloside and quercetin 3-O-rhamnoside-7-O-glucoside had the highest binding affinity in XO with a value of $-10.4 \mathrm{kcal} / \mathrm{mol}$. The glucose and prenyl groups are beneficial for quercetin in interacting with all ROS-modulating enzymes except XO. In contrast, the methoxy group negatively affects all interactions of quercetin with receptors. The perfect fit between the binding pocket and the 3D structure of the ligand greatly benefits the ligand in accessing more amino acids in the binding pocket. Their interaction stability and toxicity show that quercetin 3'-glucoside, quercetin 3,4'-diglucoside, and rutin are potent oxidative stress modulators in treating ROS-induced cancer.
\end{abstract}

Keywords: ROS-induced cancer, Quercetin derivates, Oxidative stress modulator, ROS-modulating enzymes 


\section{Introduction}

The imbalance between the number of free radicals (ROS) and reactive metabolites (antioxidants) in the body causes oxidative stress. High amounts of ROS can accelerate the oxidation process in normal cells, leading to cell damage. Premature aging and the onset of chronic diseases such as cancer are the most prominent outcomes. It is widely acknowledged that oxidative stress promotes tumor genesis and growth by causing genetic instability [36]. As a result, focusing on redox-sensitive pathways and transcription factors has significant potential for cancer prevention and treatment [10, 27]. Lipoxygenase (LOX), NADPH oxidase (NOX), and xanthine oxidase (XO) are enzymes regulating ROS generation. The inhibition of these three enzymes significantly impacts the suppression of ROS generation and cancer progression [5, 10, 16, 22, 25, 31]. Likewise, induction of the catalase (CAT), glutathione reductase (GR), glutathione peroxidase (GPx), and superoxide dismutase (SOD) can reduce ROS levels and prevent cell damage $[3,7,11,12,14$, 34].

One of the powerful natural antioxidants is quercetin. Quercetin has been shown to effectively prevent and inhibit cancer growth via the regulation of ROS [33, 35, 37]. Quercetin was reported to increase catalase activity up to $28.6 \%$ in 3-NP treated animals [29]. In addition, quercetin also inhibits the activity of several pro-oxidant enzymes such as LOX, NOX, and XO [4, 9, 17, 18, 28, 30, 37]. The activity is strongly influenced by the structure and position of functional group on quercetin (see Figure 1). The substitution of functional groups of quercetin impacts its biochemical and pharmacological properties [20, 26, 33]. Therefore, this research was conducted to study the impact of 3D structure, type, and position of quercetin moiety on its activity against ROS-modulating enzymes to develop more optimal quercetin-based drugs in treating ROS-induced cancer. The 23 natural quercetin derivates are present in fruit, seeds, tubers, and honey [21]. In this study, 23 natural quercetin derivatives were docked on 7 ROS-modulating enzymes, and then a molecular dynamics study was conducted to determine the stability of the ligand-protein interactions. Toxicity studies were also carried out to assess the safety of the test ligands.

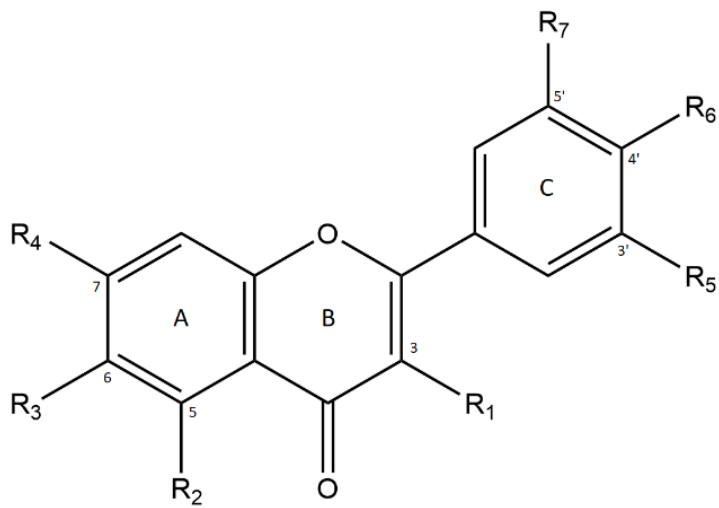

Figure 1. Quercetin basic structure.

\section{Methods}

\subsection{Ligand Preparation}

The test ligands were quercetin and its derivates found in plants [21]. Some ligand structures were downloaded from PubChem, and the rest were drawn using ChemDraw Pro 12.0 (PerkinElmer Informatics, PerkinElmer Inc, USA). Structure errors were checked using the "Check Structure" feature, and then the structures were cleaned using the "Clean Up Structure" feature in ChemDraw. The default geometry of each ligand was removed using the "Clean Geometry" feature in Discovery Studio 2021 Client (DS) (BIOVIA, San Diego, CA, USA). 
Energy minimization (MM2) was performed using Chem3D. Each ligand was then optimized using AutoDockTools 1.5.6 (ADT) (TheScripps Research Institute, USA) to add Gasteiger charges, set rotatable bonds, and TORSDOF. Furthermore, the ligands are stored in PDBQT format.

\subsection{Protein Preparation}

The structure of the proteins was obtained from the Protein Data Bank (PDB) website. The code for each protein used is lipoxygenase (3O8Y), NADPH oxidase (5O0X), xanthine oxidase (3BDJ), catalase (1DGF), glutathione reductase (1XAN), glutathione peroxidase (6ELW), and superoxide dismutase $(2 \mathrm{C} 9 \mathrm{~V})$. Native ligand and protein were separated using the DS. The protein was optimized using ADT to remove water, regulate the charges (Kollman charges), and add polar hydrogen. The protein was then stored in PDBQT format. The grid position was arranged based on the active site attached by the native ligand. The grid dimension was set to $40 \times 40 \times 40$ magnification with a spacing of $0.375 \AA$. Gridbox parameters can be seen in Table 1 .

Table 1. The ROS enzymes' gridbox parameters.

\begin{tabular}{lc}
\hline Enzymes & $\begin{array}{c}\text { Active sites } \\
\text { Coordinate }(\AA)\end{array}$ \\
\hline Lipoxygenase & $4,976 \times 21,401 \times$ \\
& 0,286 \\
NADPH Oxidase & $65,738 \times 0,875 \times$ \\
& 62,590 \\
Xanthin Oxidase & $17,175 \times-17,782 \times$ \\
& 16,527 \\
Catalase & $14,877 \times 15,793 \times$ \\
& 78,537
\end{tabular}

\begin{tabular}{lc} 
Glutathione & $82,170 \times-5,827 \times$ \\
Reductase & 36,154 \\
Glutathione & $42,474 \times 14,099 \times-$ \\
Peroxidase & 18,061 \\
Superoxide & $95,611 \times 47,146 \times$ \\
Dismutase & 112,872 \\
\hline
\end{tabular}

\subsection{Molecular Docking}

Molecular docking was performed using DockFlin software (ETFLIN, Indonesia). This software is a tool for systematically scheduling multi-ligand and multi-protein docking processes by the Autodock Vina. Ligands and proteins were added to the respective list panel, then the docking parameters per protein were loaded in the order in the grid list panel. The docking parameters used were energy range of 4 and exhaustiveness of 8 . The operating system used was Windows 10 Home Single Language 64 bit with AMD Ryzen 5 3500U, Radeon Vega Mobile Gfx 2.10 $\mathrm{GHz}$, and $\mathrm{RAM}$ of $8 \mathrm{~GB}$.

\subsection{Molecular Dynamics Study}

The protein's stable structure was studied using the CABS Flex 2.0 server, based on coarse-grained simulations of protein motion [15]. Distance restraints generator mode was SS2 with minimal restraint length of $3.8 \AA$ and maximal restraint length of $8.0 \AA$. The number of cycles and trajectory frames was set to 50 , with a global weight of 1.0 and a temperature of 1.4. The distance restraints generator was set to default values. The output of this step is ten structural models for each enzyme based on their flexibility. Each model of each enzyme was then redocked with potent ligands obtained from the molecular docking results. The fluctuation of the binding energy of each ligand-protein interaction is presented in 
the form of a line graph. This test aimed to see whether the ligand-protein interaction remains stable during attachment without losing binding energy on all models [2].

\subsection{Determination of Crucial Amino Acid}

This test was carried out to determine the most active amino acid residues at the binding site of the proteins based on the habit of a group of compounds interacting with the protein. The output file of the docking process (Autodock Vina) produced nine ligand-protein interaction models for each ligand. The active amino acid of each protein receptor was determined based on its occurrence (binding ligands via hydrogen bonds) in each model and all ligand-protein complexes. The number of occurrences has been scored using DockFlin. If an amino acid has a score of more than 9, it is easily accessible and preferred as a target for binding [32].

\subsection{Toxicity prediction of quercetin derivates}

Prediction of acute oral toxicity (LD50) was carried out using pkCSM ADMET to determine the safety of quercetin and its derivates. The SMILES string for each ligand was obtained from a PDB file converted to SMI format using DS.

\section{Results}

\subsection{Molecular Docking}

Based on the molecular docking results, it was found that quercetin has strong interactions with antioxidant and prooxidant enzymes, especially with CAT, LOX, and NOX. Quercetin and its derivatives produced binding energy in CAT of -8.9 to $-11.5 \mathrm{kcal} / \mathrm{mol}$, GR of -7.6 to $-10.5 \mathrm{kcal} / \mathrm{mol}$, GPx of -6.9 to -8.8 $\mathrm{kcal} / \mathrm{mol}$, SOD of -7.5 to $-10.2 \mathrm{kcal} / \mathrm{mol}$, LOX of -7.6 to $-10.9 \mathrm{kcal} / \mathrm{mol}$, NOX of -9.7 to $-12.8 \mathrm{kcal} / \mathrm{mol}$, and $\mathrm{XO}$ of -7.4 to -10.4 $\mathrm{kcal} / \mathrm{mol}$. Each binding energy of the test ligands can be seen in Table 2.

Table 2. Binding energy of test ligand on each ROS-modulating enzymes.

\begin{tabular}{|l|l|l|l|l|l|l|l|l|}
\hline Compound Name & Ligand Code & CAT & GR & GPx & SOD & LOX & NOX & XO \\
\hline Quercetin & Ligand 0 & -9.5 & -8.8 & -7.5 & -9 & -9.1 & -10.8 & -9.6 \\
\hline Quercetin 3-O-galactoside & Ligand 1 & -9.7 & -8.7 & -7.6 & -8.3 & -10.2 & -10.4 & -8 \\
\hline Quercetin 3-O-glucoside & Ligand 2 & -9.5 & -8.6 & -7.5 & -8.2 & -10.2 & -10.3 & -9.3 \\
\hline Quercetin 3-O-rhamnoside & Ligand 3 & -9.6 & -8.7 & -7.8 & -8.9 & -9.8 & -10.8 & -7.9 \\
\hline Quercetin 3-O-rhamnozyl-(1-6)-glucoside & Ligand 4 & -10.4 & -8.2 & -8.8 & -8.1 & -10.9 & -10.9 & -9.2 \\
\hline Quercetin 7-O-glucoside & Ligand 5 & -10.9 & -9.3 & -8.6 & -8.9 & -10.4 & -11.5 & -8.3 \\
\hline Quercetin 3-O-rhamnoside-7-O-glucoside & Ligand 6 & -9.5 & -8 & -7.3 & -7.7 & -8.7 & -9.9 & -10.4 \\
\hline Quercetin 6-C- glucoside & Ligand 7 & -10.5 & -9.9 & -8.1 & -9 & -8.9 & -11.1 & -8.1 \\
\hline Quercetin 3-(2''-acetylgalactoside) & Ligand 8 & -9 & -7.6 & -7.5 & -7.5 & -7.6 & -11 & -7.4 \\
\hline Quercetin 3-sulfate-7-O-arabinoside & Ligand 9 & -10.3 & -9.2 & -8.7 & -9.1 & -9.9 & -10.1 & -8.1 \\
\hline Quercetin 3-O-glucoside-3'-sulfate & Ligand 10 & -9.5 & -9.2 & -7.9 & -8.3 & -9.8 & -10.3 & -8 \\
\hline Quercetin 5-methyl ether & Ligand 11 & -9.4 & -8.5 & -7.3 & -7.8 & -8.9 & -9.7 & -8.9 \\
\hline Quercetin 7- methyl ether & Ligand 12 & -9.4 & -7.8 & -7.4 & -8.8 & -8.9 & -10.6 & -7.7 \\
\hline Quercetin 3'- methyl ether & Ligand 13 & -9.4 & -8.5 & -7.3 & -8.8 & -8.3 & -10.7 & -8.7 \\
\hline Quercetin 4'- methyl ether & Ligand 14 & -9.4 & -8.5 & -7.5 & -8.5 & -8.7 & -10.6 & -9.5 \\
\hline Quercetin 7-methoxy-3-O-glucoside & Ligand 15 & -10 & -8.2 & -7.6 & -8.2 & -9.7 & -10.7 & -8 \\
\hline
\end{tabular}




\begin{tabular}{|l|l|c|c|c|c|c|c|c|}
\hline Quercetin 3'- methoxy -3-O-galactoside & Ligand 16 & -9.9 & -8 & -7.5 & -8.3 & -9 & -10.3 & -7.9 \\
\hline 6,5'-Di-C-prenylquercetin & Ligand 17 & -10.3 & -9.1 & -8.4 & -9.4 & -10.6 & -11.7 & -9.1 \\
\hline Quercetin 3-O-xyloside & Ligand 18 & -9.8 & -8.2 & -7.5 & -8.3 & -9.5 & -9.9 & -10.4 \\
\hline Quercetin 3-O-glucuronide & Ligand 19 & -9.9 & -8.3 & -8.4 & -8.4 & -10.1 & -10.9 & -9.9 \\
\hline Quercetin 3,4'-diglucoside & Ligand 20 & -11.5 & -10.5 & -8.7 & -9.3 & -10.6 & -10 & -8.3 \\
\hline Quercetin 3-O-6' -acetylglucoside & Ligand 21 & -11 & -8.4 & -7.8 & -7.9 & -10.3 & -11.2 & -7.8 \\
\hline Quercetin 3,3'-dimethyl ether & Ligand 22 & -8.9 & -8 & -6.9 & -8.6 & -8.1 & -10.3 & -8.8 \\
\hline Quercetin 3'-glucoside & Ligand 23 & -11.2 & -9.8 & -8.8 & -10.2 & -10.7 & -12.8 & -8.8 \\
\hline
\end{tabular}

In the XO enzyme, structural modification of quercetin will generally decrease its binding energy except for the substitution of xylose and glucuronate at the C-3 atom. In other enzymes, the substitution of glucose, prenyl, arabinose, and glucuronate groups generally increases the binding energy of quercetin. However, the binding energy of quercetin can be decreased if there is a methoxy group as an alkyl group. The increasing or decreasing percentage in the binding energy of quercetin based on its functional group can be seen in Table 3 .

Table 3. Changes in binding energy due to the influence of substituents

\begin{tabular}{|c|c|c|c|c|c|c|c|c|c|c|c|c|c|c|c|}
\hline \multirow{2}{*}{$\begin{array}{l}\text { Ligand } \\
\text { Code }\end{array}$} & \multicolumn{7}{|c|}{ Moiety position } & \multicolumn{8}{|c|}{ Differences in binding energy $(\%) *$} \\
\hline & R1 & $\mathbf{R} 2$ & R3 & R4 & $\mathbf{R 5}$ & R6 & $\mathbf{R 7}$ & CAT & GR & GPx & SOD & LOX & NOX & XO & Average \\
\hline Ligand 23 & $\mathrm{OH}$ & $\mathrm{OH}$ & $\mathrm{H}$ & $\mathrm{OH}$ & Glu & $\mathrm{OH}$ & $\mathrm{H}$ & 17.9 & 11.4 & 17.3 & 13.3 & 17.6 & 18.5 & -8.3 & 12.5 \\
\hline Ligand 20 & Glu & $\mathrm{OH}$ & $\mathrm{H}$ & $\mathrm{OH}$ & $\mathrm{OH}$ & Glu & $\mathrm{H}$ & 21.1 & 19.3 & 16.0 & 3.3 & 16.5 & -7.4 & -13.5 & 7.9 \\
\hline Ligand 17 & $\mathrm{OH}$ & $\mathrm{OH}$ & Pre & $\mathrm{OH}$ & $\mathrm{OH}$ & $\mathrm{OH}$ & Pre & 8.4 & 3.4 & 12.0 & 4.4 & 16.5 & 8.3 & -5.2 & 6.8 \\
\hline Ligand 5 & $\mathrm{OH}$ & $\mathrm{OH}$ & $\mathrm{H}$ & Glu & $\mathrm{OH}$ & $\mathrm{OH}$ & $\mathrm{H}$ & 14.7 & 5.7 & 14.7 & -1.1 & 14.3 & 6.5 & -13.5 & 5.9 \\
\hline Ligand 4 & $\begin{array}{c}\text { Glu } \\
\& \\
\text { Rha }\end{array}$ & $\mathrm{OH}$ & $\mathrm{H}$ & $\mathrm{OH}$ & $\mathrm{OH}$ & $\mathrm{OH}$ & $\mathrm{H}$ & 9.5 & -6.8 & 17.3 & -10.0 & 19.8 & 0.9 & -4.2 & 3.8 \\
\hline Ligand 19 & $\mathrm{Gcr}$ & $\mathrm{OH}$ & $\mathrm{H}$ & $\mathrm{OH}$ & $\mathrm{OH}$ & $\mathrm{OH}$ & $\mathrm{H}$ & 4.2 & -5.7 & 12.0 & -6.7 & 11.0 & 0.9 & 3.1 & 2.7 \\
\hline Ligand 9 & Sul & $\mathrm{OH}$ & $\mathrm{H}$ & Ara & $\mathrm{OH}$ & $\mathrm{OH}$ & $\mathrm{H}$ & 8.4 & 4.5 & 16.0 & 1.1 & 8.8 & -6.5 & -15.6 & 2.4 \\
\hline Ligand 7 & $\mathrm{OH}$ & $\mathrm{OH}$ & Glu & $\mathrm{OH}$ & $\mathrm{OH}$ & $\mathrm{OH}$ & $\mathrm{H}$ & 10.5 & 12.5 & 8.0 & 0.0 & -2.2 & 2.8 & -15.6 & 2.3 \\
\hline Ligand 21 & $6-A$ & $\mathrm{OH}$ & $\mathrm{H}$ & $\mathrm{OH}$ & $\mathrm{OH}$ & $\mathrm{OH}$ & $\mathrm{H}$ & 15.8 & -4.5 & 4.0 & -12.2 & 13.2 & 3.7 & -18.8 & 0.2 \\
\hline Ligand 0 & $\mathrm{OH}$ & $\mathrm{OH}$ & $\mathrm{H}$ & $\mathrm{OH}$ & $\mathrm{OH}$ & $\mathrm{OH}$ & $\mathrm{H}$ & 0.0 & 0.0 & 0.0 & 0.0 & 0.0 & 0.0 & 0.0 & 0.0 \\
\hline Ligand 2 & Glu & $\mathrm{OH}$ & $\mathrm{H}$ & $\mathrm{OH}$ & $\mathrm{OH}$ & $\mathrm{OH}$ & $\mathrm{H}$ & 0.0 & -2.3 & 0.0 & -8.9 & 12.1 & -4.6 & -3.1 & -1.0 \\
\hline Ligand 18 & Xyl & $\mathrm{OH}$ & $\mathrm{H}$ & $\mathrm{OH}$ & $\mathrm{OH}$ & $\mathrm{OH}$ & $\mathrm{H}$ & 3.2 & -6.8 & 0.0 & -7.8 & 4.4 & -8.3 & 8.3 & -1.0 \\
\hline Ligand 3 & Rha & $\mathrm{OH}$ & $\mathrm{H}$ & $\mathrm{OH}$ & $\mathrm{OH}$ & $\mathrm{OH}$ & $\mathrm{H}$ & 1.1 & -1.1 & 4.0 & -1.1 & 7.7 & 0.0 & -17.7 & -1.0 \\
\hline Ligand 10 & Glu & $\mathrm{OH}$ & $\mathrm{H}$ & $\mathrm{OH}$ & Sul & $\mathrm{OH}$ & $\mathrm{H}$ & 0.0 & 4.5 & 5.3 & -7.8 & 7.7 & -4.6 & -16.7 & -1.6 \\
\hline Ligand 1 & Gal & $\mathrm{OH}$ & $\mathrm{H}$ & $\mathrm{OH}$ & $\mathrm{OH}$ & $\mathrm{OH}$ & $\mathrm{H}$ & 2.1 & -1.1 & 1.3 & -7.8 & 12.1 & -3.7 & -16.7 & -2.0 \\
\hline Ligand 14 & $\mathrm{OH}$ & $\mathrm{OH}$ & $\mathrm{H}$ & $\mathrm{OH}$ & $\mathrm{OH}$ & Met & $\mathrm{H}$ & -1.1 & -3.4 & 0.0 & -5.6 & -4.4 & -1.9 & -1.0 & -2.5 \\
\hline Ligand 15 & Glu & $\mathrm{OH}$ & $\mathrm{H}$ & Met & $\mathrm{OH}$ & $\mathrm{OH}$ & $\mathrm{H}$ & 5.3 & -6.8 & 1.3 & -8.9 & 6.6 & -0.9 & -16.7 & -2.9 \\
\hline Ligand 13 & $\mathrm{OH}$ & $\mathrm{OH}$ & $\mathrm{H}$ & $\mathrm{OH}$ & Met & $\mathrm{OH}$ & $\mathrm{H}$ & -1.1 & -3.4 & -2.7 & -2.2 & -8.8 & -0.9 & -9.4 & -4.1 \\
\hline Ligand 6 & Rha & $\mathrm{OH}$ & $\mathrm{H}$ & Glu & $\mathrm{OH}$ & $\mathrm{OH}$ & $\mathrm{H}$ & 0.0 & -9.1 & -2.7 & -14.4 & -4.4 & -8.3 & 8.3 & -4.4 \\
\hline Ligand 16 & Gal & $\mathrm{OH}$ & $\mathrm{H}$ & $\mathrm{OH}$ & Met & $\mathrm{OH}$ & $\mathrm{H}$ & 4.2 & -9.1 & 0.0 & -7.8 & -1.1 & -4.6 & -17.7 & -5.2 \\
\hline Ligand 12 & $\mathrm{OH}$ & $\mathrm{OH}$ & $\mathrm{H}$ & Met & $\mathrm{OH}$ & $\mathrm{OH}$ & $\mathrm{H}$ & -1.1 & -11.4 & -1.3 & -2.2 & -2.2 & -1.9 & -19.8 & -5.7 \\
\hline Ligand 11 & $\mathrm{OH}$ & Met & $\mathrm{H}$ & $\mathrm{OH}$ & $\mathrm{OH}$ & $\mathrm{OH}$ & $\mathrm{H}$ & -1.1 & -3.4 & -2.7 & -13.3 & -2.2 & -10.2 & -7.3 & -5.7 \\
\hline Ligand 22 & Met & $\mathrm{OH}$ & $\mathrm{H}$ & $\mathrm{OH}$ & Met & $\mathrm{OH}$ & $\mathrm{H}$ & -6.3 & -9.1 & -8.0 & -4.4 & -11.0 & -4.6 & -8.3 & -7.4 \\
\hline
\end{tabular}




\begin{tabular}{|l|c|c|c|c|c|c|c|c|c|c|c|c|c|c|c|}
\hline Ligand 8 & 2-A & OH & H & OH & OH & OH & H & -5.3 & -13.6 & 0.0 & -16.7 & -16.5 & 1.9 & -22.9 & -10.4 \\
\hline
\end{tabular}

Note: $\mathrm{Glu}=$ glucose, $\mathrm{Met}=$ methoxy, $\mathrm{Rha}=$ rhamnose, $\mathrm{Sul}=$ sulfate, $\mathrm{Gal}=$ galactose, Pre $=$ prenyl, Gcr = glucuronate, Ara = arabinose, 6-A = 6-acetylglucose, 2-A = 2-acetylgalactose, and $\mathrm{Xyl}=$ xylose. $*$ A negative percentage indicates a reduction in binding affinity and a positive percentage indicates an increase in binding affinity (compared to basic quercetin).

\subsection{Molecular Dynamics Study}

Molecular dynamics simulations were only carried out on enzymes that have strong potential to become targets of quercetin derivatives, namely CAT, LOX, and NOX. Based on the molecular dynamics simulation, it can be seen that the flexibility of the protein structure does not change the $3 \mathrm{D}$ pattern of the enzyme significantly (see Figure 2). Each enzyme's binding site retains a similar shape and coordinates to not interfere with the ligand binding.
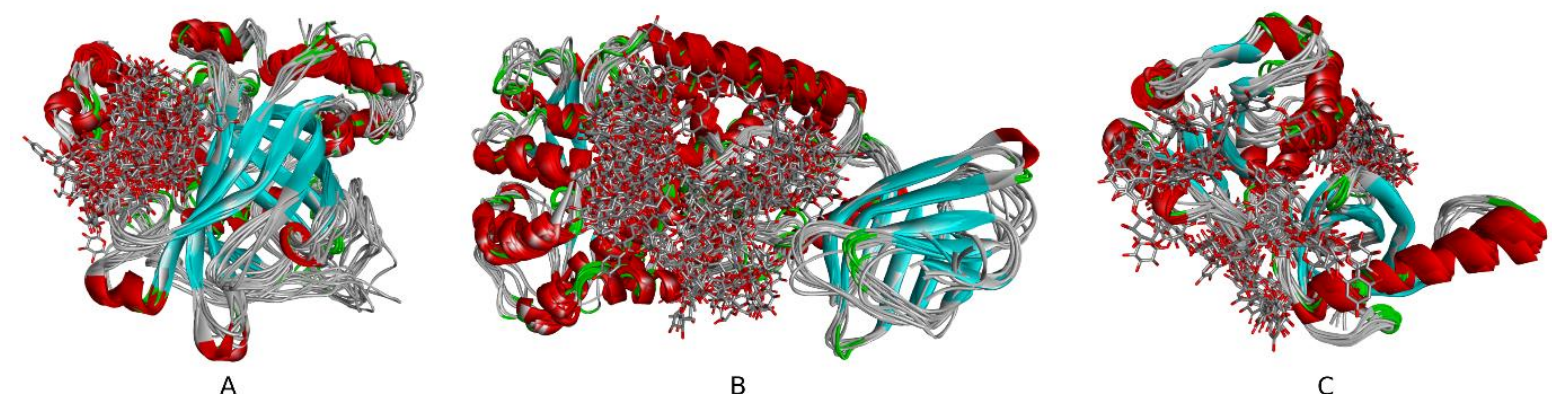

Figure 2. Simulation of protein flexibility and ligand-protein dynamics interaction of (A) quercetin 3,4'-diglucoside and CAT, (B) quercetin 3-O-rhamnozyl-(1 $\rightarrow 6)$-glucoside and LOX, and (C) quercetin 3'-glucoside and NOX.

After re-docking the potent ligands on each model of the three target enzymes, it was found that the interactions of CAT-Ligand 20, LOX-Ligand 4, and NOX-Ligand 23 remained stable without losing binding energy in any of the models. The average binding energies of CAT-Ligand 20, LOXLigand 4, and NOX-Ligand 23 were -9.06 $\pm 0.55,-9.02 \pm 0.97$, and $8.77 \pm 0.48$ $\mathrm{kcal} / \mathrm{mol}$. The fluctuations of the three interactions can be seen in Figure 2.

\subsection{Determination of Crucial Amino Acid}

Based on the scoring results, it is known that the CAT enzyme has ten crucial amino acids that were active in forming hydrogen bonds with compounds from the quercetin group. In LOX, there are four crucial amino acids, while in NOX, there are nine crucial amino acids. The average bond length, hydrogen bond types, and scores of each amino acid in each enzyme can be seen in Table 4.

\subsection{Toxicity prediction of quercetin derivates}

Toxicity data of each test ligand can be seen in Table 5. Ligand 22 has the highest dose tolerance, while ligand 4 has the lowest dose tolerance. The predicted dose is recommended for use in phase I clinical trials. All tested ligands are non-toxic to the liver and do not induce skin sensitization. 


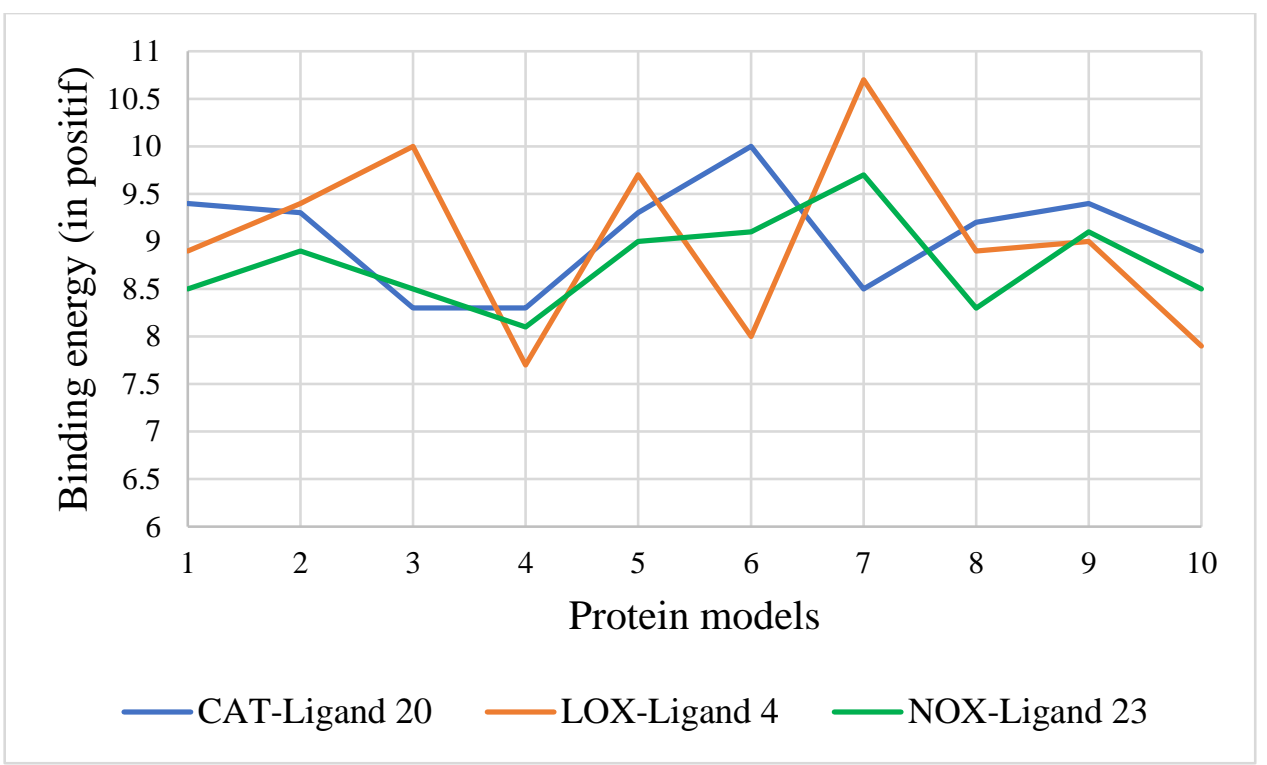

Figure 3. Fluctuations in the binding energy of CAT-Ligand 20, LOX-Ligand 4, and NOXLigand 23 in each model.

Table 4. The crucial amino acid at the binding sites of CAT, LOX, and NOX.

\begin{tabular}{|c|c|c|c|c|}
\hline \multirow{5}{*}{ Enzyme } & $\begin{array}{c}\text { Crucial } \\
\text { Amino } \\
\text { Acids }\end{array}$ & $\begin{array}{c}\text { Average } \\
\text { Bond Length } \\
(\AA)\end{array}$ & Average Bond Type & Score \\
\hline \multirow{5}{*}{ CAT } & His305 & 4.638 & Conventional Hydrogen & 36.91 \\
\cline { 2 - 5 } & Arg203 & 4.475 & Conventional Hydrogen & 22.64 \\
\cline { 2 - 5 } & His305 & 4.587 & Carbon Donor Hydrogen & 19.73 \\
\cline { 2 - 5 } & Phe446 & 4.695 & Carbon Donor Hydrogen & 19.55 \\
\cline { 2 - 5 } & Phe198 & 4.52 & Carbon Donor Hydrogen & 19.09 \\
\cline { 2 - 5 } & Ser201 & 3.971 & Conventional Hydrogen & 14.36 \\
\cline { 2 - 5 } & Asp202 & 4.715 & Conventional Hydrogen & 11.64 \\
\cline { 2 - 5 } & His194 & 4.487 & Conventional Hydrogen & 11.09 \\
\cline { 2 - 5 } & Gln442 & 4.38 & Conventional Hydrogen & 9.41 \\
\cline { 2 - 5 } & Ala445 & 5.076 & Carbon Donor Hydrogen & 9.14 \\
\hline \multirow{5}{*}{ LOX } & Asp170 & 4.672 & Conventional Hydrogen & 16.50 \\
\cline { 2 - 5 } & Val243 & 4.598 & Conventional Hydrogen & 16.27 \\
\cline { 2 - 5 } & Asp442 & 4.728 & Conventional Hydrogen & 9.41 \\
\cline { 2 - 5 } & Ser447 & 4.544 & Conventional Hydrogen & 9.00 \\
\hline \multirow{5}{*}{ NOX } & Thr462 & 3.74 & Conventional Hydrogen & 29.05 \\
\cline { 2 - 5 } & Arg478 & 4.09 & Conventional Hydrogen & 23.14 \\
\cline { 2 - 5 } & Pro460 & 4.41 & Conventional Hydrogen & 23.14 \\
\cline { 2 - 5 } & Phe461 & 4.44 & Carbon Donor Hydrogen & 18.68 \\
\cline { 2 - 5 } & Thr462 & 4.66 & Carbon Donor Hydrogen & 12.18 \\
\cline { 2 - 5 } & His459 & 4.81 & Carbon Donor Hydrogen & 10.82 \\
\cline { 2 - 5 } & Pro460 & 5.17 & Carbon Donor Hydrogen & 10.32 \\
\cline { 2 - 5 } & Thr484 & 4.24 & Conventional Hydrogen & 9.77 \\
\cline { 2 - 5 } & Trp695 & 4.43 & Conventional Hydrogen & 9.41 \\
\hline
\end{tabular}


Table 5. Toxicity prediction of quercetin derivates.

\begin{tabular}{|c|c|c|c|}
\hline Ligand & $\begin{array}{l}\text { Max. tolerated } \\
\text { human dose } \\
\text { (mg/KgBW/day) }\end{array}$ & Hepatotoxicity & Skin Sensitisation \\
\hline Ligand 0 & 5.13 & No & No \\
\hline Ligand 1 & 15.10 & No & No \\
\hline Ligand 2 & 12.85 & No & No \\
\hline Ligand 3 & 8.93 & No & No \\
\hline Ligand 4 & 2.62 & No & No \\
\hline Ligand 5 & 8.38 & No & No \\
\hline Ligand 6 & 10.02 & No & No \\
\hline Ligand 7 & 3.05 & No & No \\
\hline Ligand 8 & 5.77 & No & No \\
\hline Ligand 9 & 3.23 & No & No \\
\hline Ligand 10 & 8.93 & No & No \\
\hline Ligand 11 & 5.62 & No & No \\
\hline Ligand 12 & 4.15 & No & No \\
\hline Ligand 13 & 3.14 & No & No \\
\hline Ligand 14 & 5.19 & No & No \\
\hline Ligand 15 & 4.36 & No & No \\
\hline Ligand 16 & 6.59 & No & No \\
\hline Ligand 17 & 6.59 & No & No \\
\hline Ligand 18 & 6.92 & No & No \\
\hline Ligand 19 & 6.55 & No & No \\
\hline Ligand 20 & 7.67 & No & No \\
\hline Ligand 21 & 8.83 & No & No \\
\hline Ligand 22 & 7.48 & No & No \\
\hline Ligand 23 & 12.42 & No & No \\
\hline
\end{tabular}

\section{Discussion}

Quercetin is a powerful natural antioxidant. Changes in functional groups in the basic structure of quercetin will have a significant effect on its pharmacological activity [20, 26, 33]. This study found that the dimensions, position, and type of substituent functional groups of quercetin significantly affect their interactions with ROS-modulating enzymes. The most abundant substituent groups in quercetin derivatives were glucose (9 compounds), followed by methoxy (7 compounds), rhamnose (3 compounds), sulfate (2 compounds), galactose (2 compounds), prenyl, glucuronate, arabinose, 6acetylglucose, 2-acetylgalactose, and xylose. The basic structure of quercetin can be seen in Figure 1.

Based on the molecular docking results, it was found that, on average, quercetin and its derivatives only bind strongly to CAT, LOX, and NOX enzymes. The mean binding energies for GR, GPx, SOD, and XO were $-8.67 \pm 0.708,-7.85 \pm 0.566,-8.56$ \pm 0.61 , and $-8.67 \pm 0.854 \mathrm{kcal} / \mathrm{mol}$, respectively. Meanwhile, the average 
binding energy of CAT, LOX, and NOX were $-9.938 \pm 0.69,-9,538 \pm 0.9$, and $10,688 \pm 0.676 \mathrm{kcal} / \mathrm{mol}$, respectively. Quercetin was reported to have no significant effect on glutathione reductase and glutathione peroxidase [8]. SOD activity is also said to not increase significantly after being given quercetin [19]. However, some quercetin derivatives still provide high binding affinity for all enzymes, except GPx.

Quercetin 3,4'-diglucoside produced the highest binding energies for CAT and GR at -11.5 and $-10.5 \mathrm{kcal} / \mathrm{mol}$, respectively. The highest binding affinity for SOD and NOX was produced by quercetin 3'glucoside with a binding energy of -10.2 and $-12.8 \mathrm{kcal} / \mathrm{mol}$. Rutin (ligand 4) had the highest binding affinity at LOX (-10.9). Quercetin 3-O-xyloside and quercetin 3-Orhamnoside-7-O-glucoside produced the highest binding affinity in $\mathrm{XO}$ with a value of $-10.4 \mathrm{kcal} / \mathrm{mol}$. Based on these values, it can be seen that all quercetin derivatives that have a glucose group as a substituent

are potent ligands for all enzymes. The effect depends strongly on the position of glucose [38, 39]. Glucose substituents in rings $\mathrm{A}$ and $\mathrm{C}$ are the main contributors to quercetin activity. In Table 3, it can be seen that the substitution of glucose on the 3-O atom did not significantly increase the binding affinity of all enzymes, except LOX. The glucose group on the $\mathrm{C}$ ring of quercetin (see Figure 1) increases binding affinity significantly in all enzymes except XO. Still, it decreases considerably in NOX if there is another group on the 3-O atom. It is because other groups on the 3-O atom affect the position of the ligand entry into the NOX binding pocket (see Figure 4). The 3-O atom's glucose group appears to bind the residue outside the binding pocket, causing the ligand to become stranded outside. It caused quercetin 3,4'diglucoside (see Figure 4B) to lose the four hydrogen bonds it would have formed if it had managed to fit snugly into the binding pocket like quercetin 3'-glucoside (see Figure 4A).

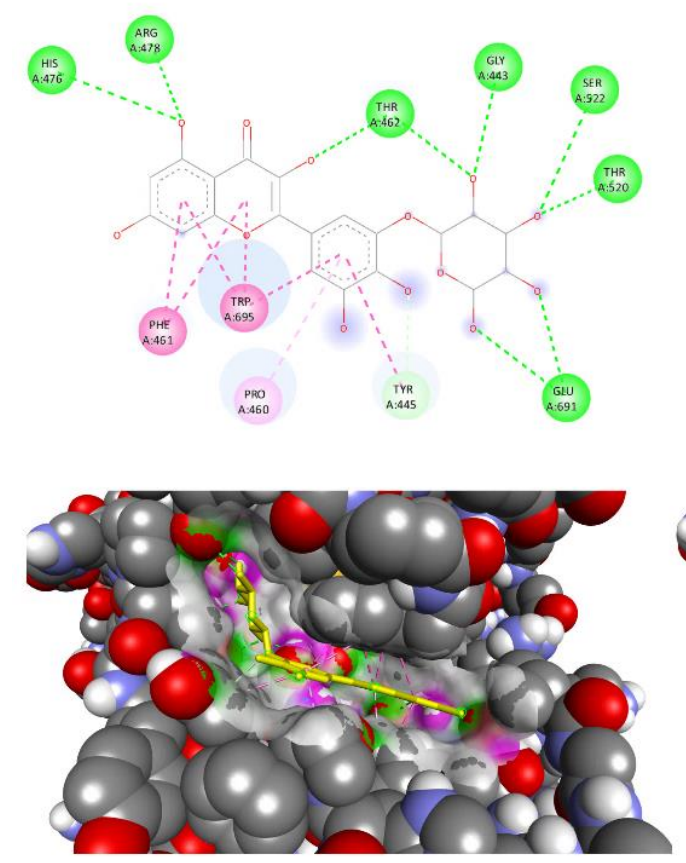

A

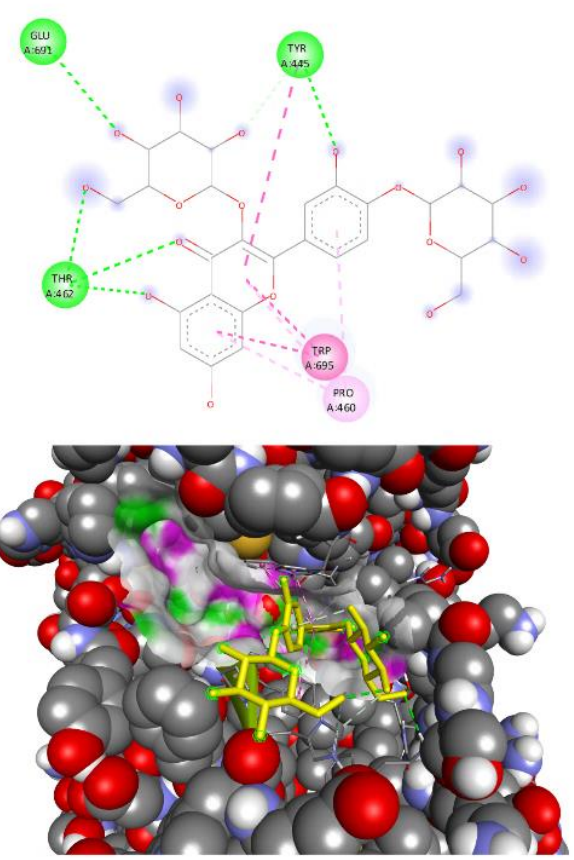

B

Figure 4. Quercetin 3'-glucoside (A) and quercetin 3,4'-diglucoside (B) on NOX binding pocket. 


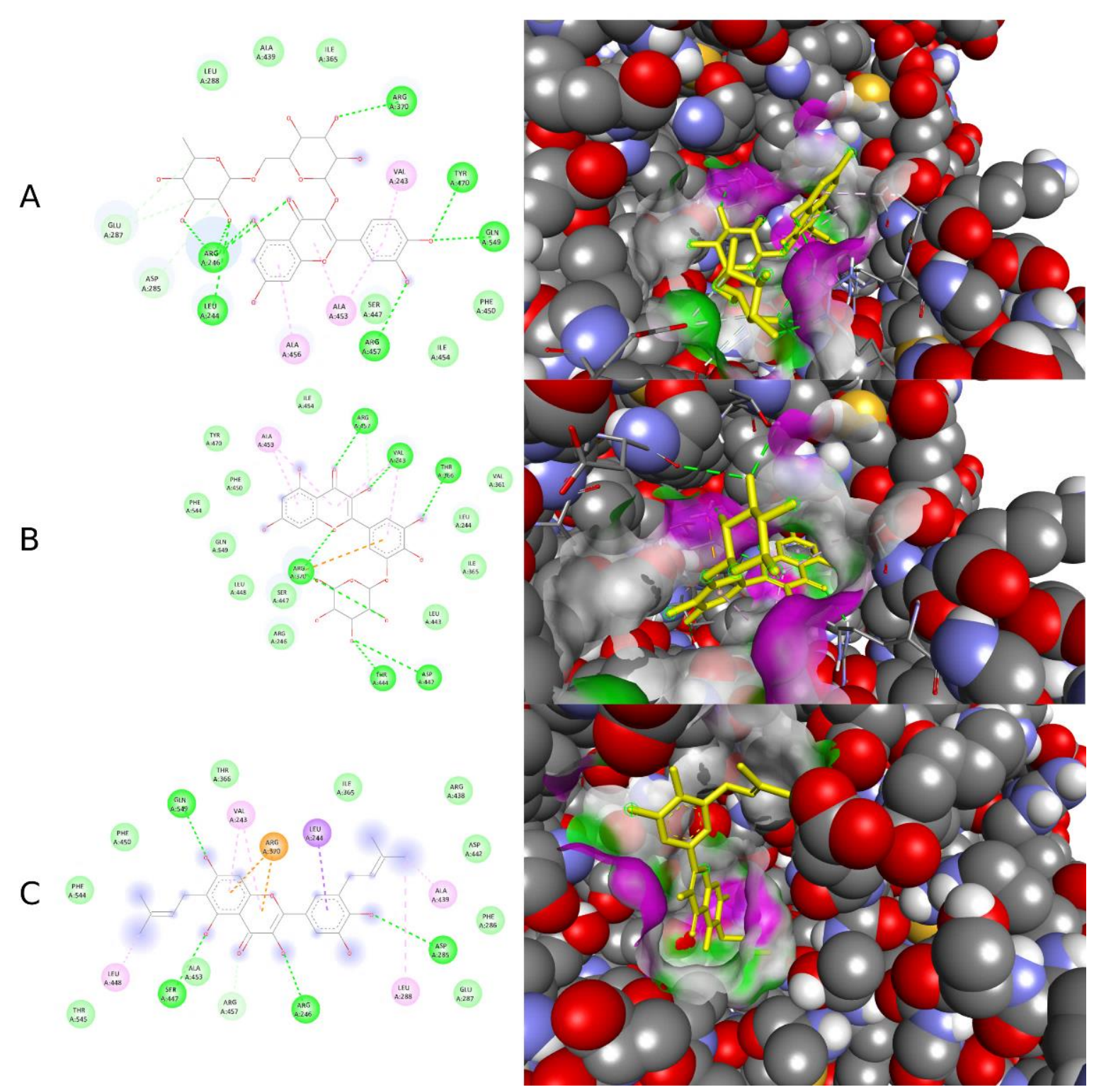

Figure 4. Interaction of rutin (A), quercetin 3'-glucoside (B), and 6,5'-Di-C-prenylquercetin (C) on LOX binding pocket in 2D and $3 \mathrm{D}$.

In the LOX enzyme, glucose and rhamnose complex (rutin) produced the highest binding affinity, followed by quercetin 3'glucoside and 6,5'-Di-C-prenylquercetin. This is due to the broader dimensions of the binding pocket so that ligand with large 3D volumes can reach and interact more with amino acid residues. In Figure 5, it can be seen that rutin forms nine conventional hydrogen bonds and two hydrogen carbons, quercetin 3'-glucoside forms seven conventional hydrogen bonds and one hydrogen carbon. In comparison, Di-Cprenylquercetin only includes four conventional hydrogen bonds and one hydrogen carbon. In contrast to rutin, quercetin 3'-glucoside and 6,5'-Di-Cprenylquercetin have a slender and elongated structure so that they bind amino acids that are only in the elongation pathway. For that, it is more suited to the extended binding pocket like the NOX.

In addition to the glucose group, the prenyl group also significantly increased the binding affinity of quercetin in all enzymes except XO. The compound 6,5'-Di-Cprenylquercetin binds strongly to the LOX. 
The two prenyl groups at the ends of the quercetin structure act as anchors and anchors to the LOX binding pocket and form pi-alkyl bonds with the amino acids Ala439 and Leu448 (see Figure 5C). Adding a prenyl group often increases the pharmacological activity of aromatic compounds such as quercetin [1, 6, 13]. Prenylation of the flavonoid structure can also enhance the bioavailability, allowing the effect to last longer [24].

The 2-acetylgalactose, methoxy, xylose, and sulphate groups have a terrible effect on the activity of quercetin. The acetyl group at the $\mathrm{C}-2$ position prevents the formation of hydrogen bonds from the galactose hydroxy group. All ligands with a methoxy group had their hydrogen bonds with all enzymes weaken. Research conducted by Z. Sroka et al. (2017) also showed decreased activity due to a methoxy group in ring B of quercetin [30]. The methoxy group can block the formation of hydrogen bonds or weaken them [23]. In $\mathrm{XO}$, all substitutions on atoms other than $\mathrm{C}$ 3 (R3) will decrease the binding affinity of quercetin. Xylose, rhamnose, and glucuronate are favorable C-3 substituents for quercetin and $\mathrm{XO}$ interactions.

Crucial amino acids were obtained by scoring their presence in binding to ligands in each Autodock Vina docking output model. Amino acids that get a score of more than nine can be said to be easily accesible and form hydrogen bonds in every interaction model. The more derivatives used, the more accurate the results for that group of compounds. Molecular docking results showed that potent ligands such as quercetin 3'-glucoside, quercetin 3,4'diglucoside, and rutin formed hydrogen bonds with crucial amino acid residues to produce stable bonds in each flexible model of the enzyme. Based on toxicity studies, quercetin 3'-glucoside and quercetin 3,4'diglucoside have a higher dose tolerance than quercetin, are non-hepatotoxic, and do not induce skin sensitization.

\section{Conclusion}

Some quercetin derivatives produce greater binding affinity than basic quercetin. The 3D volume of the structure, type, and position of the substituent groups plays a significant role in determining the interaction of quercetin and ROSmodulating enzymes. The glucose and prenyl groups are beneficial for quercetin in interacting with all ROS-modulating enzymes except XO. In contrast, the methoxy group negatively affects all interactions of quercetin with receptors. Based on molecular docking studies, interaction stability, and toxicity, we conclude that quercetin 3'-glucoside, quercetin 3,4'-diglucoside, and rutin are potent oxidative stress modulators in treating ROS-induced cancer with the binding energy of $-12.8 \mathrm{kcal} / \mathrm{mol},-11.5$ and $-10.5 \mathrm{kcal} / \mathrm{mol}$, respectively.

\section{Acknowledgement}

The authors are thankful to Chusnul Nur Ramadhani for her assistance in finding the quercetin derivates.

\section{References}

1. Alhassan A, Abdullahi M, Uba A, Umar A (2014) Prenylation of Aromatic Secondary Metabolites: A New Frontier for Development of Novel Drugs. Trop J Pharm Res 13:307. doi: 10.4314/tjpr.v13i2.22

2. Arora S, Lohiya G, Moharir K, Shah S, Yende S (2020) Identification of Potential Flavonoid Inhibitors of the 
SARS-CoV-2 Main Protease 6YNQ: A Molecular Docking Study. Digit Chinese Med 3:239-248. doi: 10.1016/j.dcmed.2020.12.003

3. Bauer G (2012) Tumor cell-protective catalase as a novel target for rational therapeutic approaches based on specific intercellular ROS signaling. Anticancer Res 32:2599-2624

4. Bindoli A, Valente M, Cavallini L (1985) Inhibitory action of quercetin on xanthine oxidase and xanthine dehydrogenase activity. Pharmacol Res Commun 17:831-839. doi: 10.1016/0031-6989(85)90041-4

5. Bishayee K, Khuda-Bukhsh AR (2013) 5-Lipoxygenase Antagonist therapy: a new approach towards targeted cancer chemotherapy. Acta Biochim Biophys Sin (Shanghai) 45:709-719. doi: 10.1093/abbs/gmt064

6. Botta B, Vitali A, Menendez P, Misiti D, Monache G (2005) Prenylated Flavonoids: Pharmacology and Biotechnology. Curr Med Chem 12:713-739. doi: $10.2174 / 0929867053202241$

7. Chen B, Shen Z, Wu D, Xie X, Xu X, Lv L, Dai H, Chen J, Gan X (2019) Glutathione Peroxidase 1 Promotes NSCLC Resistance to Cisplatin via ROS-Induced Activation of PI3K/AKT Pathway. Biomed Res Int 2019:1-12. doi: $10.1155 / 2019 / 7640547$

8. Degroote J, Vergauwen H, Van Noten N, Wang W, De Smet S, Van Ginneken C, Michiels J (2019) The Effect of Dietary Quercetin on the Glutathione Redox System and Small Intestinal Functionality of Weaned Piglets. Antioxidants 8:312. doi: 10.3390/antiox 8080312

9. Doucet MS, Jougleux J-L, Poirier SJ, Cormier M, Léger JL, Surette ME,
Pichaud N, Touaibia M, Boudreau LH (2019) Identification of Peracetylated Quercetin as a Selective 12Lipoxygenase Pathway Inhibitor in Human Platelets. Mol Pharmacol 95:139-150. doi: 10.1124/mol.118.113480

10. Gào X, Schöttker B (2017) Reductionoxidation pathways involved in cancer development: a systematic review of literature reviews. Oncotarget 8:51888-51906. doi: 10.18632/oncotarget.17128

11. Glorieux C, Calderon PB (2018) Catalase down-regulation in cancer cells exposed to arsenic trioxide is involved in their increased sensitivity to a pro-oxidant treatment. Cancer Cell Int 18:24. doi: 10.1186/s12935-0180524-0

12. Goh J, Enns L, Fatemie S, Hopkins H, Morton J, Pettan-Brewer C, Ladiges W (2011) Mitochondrial targeted catalase suppresses invasive breast cancer in mice. BMC Cancer 11:191. doi: 10.1186/1471-2407-11-191

13. Hošek J, Toniolo A, Neuwirth $O$, Bolego C (2013) Prenylated and Geranylated Flavonoids Increase Production of Reactive Oxygen Species in Mouse Macrophages but Inhibit the Inflammatory Response. J Nat Prod 76:1586-1591. doi: 10.1021/np400242e

14. Kennedy L, Sandhu JK, Harper ME, Cuperlovic-culf M (2020) Role of glutathione in cancer: From mechanisms to therapies. Biomolecules 10:1-27. doi: 10.3390/biom10101429

15. Kurcinski M, Oleniecki T, Ciemny MP, Kuriata A, Kolinski A, Kmiecik S (2019) CABS-flex standalone: a simulation environment for fast modeling of protein flexibility. Bioinformatics 35:694-695. doi: 


\subsection{3/bioinformatics/bty685}

16. Landry WD, Cotter TG (2014) ROS signalling, NADPH oxidases and cancer. Biochem Soc Trans 42:934938. doi: 10.1042/BST20140060

17. Luo M, Tian R, Lu N (2020) Quercetin Inhibited Endothelial Dysfunction and Atherosclerosis in Apolipoprotein EDeficient Mice: Critical Roles for NADPH Oxidase and Heme Oxygenase-1. J Agric Food Chem 68:10875-10883. doi: 10.1021/acs.jafc.0c03907

18. Luo M, Tian R, Yang Z, Peng Y-Y, Lu $N$ (2019) Quercetin suppressed NADPH oxidase-derived oxidative stress via heme oxygenase-1 induction in macrophages. Arch Biochem Biophys 671:69-76. doi: 10.1016/j.abb.2019.06.007

19. Martín MJ, La -Casa C, Alarcón-de-laLastra C, Cabeza J, Villegas I, Motilva V (1998) Anti-Oxidant Mechanisms Involved in Gastroprotective Effects of Quercetin. Zeitschrift für Naturforsch C 53:82-88. doi: 10.1515/znc-1998-1215

20. Massi A, Bortolini O, Ragno D, Bernardi T, Sacchetti G, Tacchini M, De Risi C (2017) Research Progress in the Modification of Quercetin Leading to Anticancer Agents. Molecules 22:1270. doi: 10.3390/molecules 22081270

21. Materska M (2008) Quercetin and Its Derivatives: Chemical Structure and Bioactivity -a Review. Polish J food Nutr Sci 58:407-413

22. Meitzler JL, Antony S, Wu Y, Juhasz A, Liu H, Jiang G, Lu J, Roy K, Doroshow JH (2014) NADPH Oxidases: A Perspective on Reactive Oxygen Species Production in Tumor Biology. Antioxid Redox Signal 20:2873-2889.

\subsection{9/ars.2013.5603}

23. Muchtaridi YA, Megantara S, Purnomo H (2018) Kimia Medisinal: Dasar-Dasar dalam Perancangan Obat (Pertama). Prenamedia Group, Jakarta

24. Mukai R (2018) Prenylation enhances the biological activity of dietary flavonoids by altering their bioavailability. Biosci Biotechnol Biochem 82:207-215. doi: 10.1080/09168451.2017.1415750

25. Oh S-H, Choi S-Y, Choi H-J, Ryu HM, Kim Y-J, Jung H-Y, Cho J-H, Kim C-D, Park S-H, Kwon T-H, Kim Y-L (2019) The emerging role of xanthine oxidase inhibition for suppression of breast cancer cell migration and metastasis associated with hypercholesterolemia. FASEB J 33:7301-7314. doi: 10.1096/fj.201802415RR

26. Panche AN, Diwan AD, Chandra SR (2016) Flavonoids: an overview. J Nutr Sci 5:e47. doi: 10.1017/jns.2016.41

27. Reuter S, Gupta SC, Chaturvedi MM, Aggarwal BB (2010) Oxidative stress, inflammation, and cancer: How are they linked? Free Radic Biol Med 49:1603-1616. doi: 10.1016/j.freeradbiomed.2010.09.006

28. Sanda V, Ioana S, Socaciu C, Nagaya $\mathrm{T}$, Oduor Ogola HJ, Yokota K, Nishimura K, Jisak M (2012) Lipoxygenase-Quercetin Interaction: A Kinetic Study Through Biochemical and Spectroscopy Approaches. In: Biochemical Testing. InTech

29. Sandhir R, Mehrotra A (2013) Quercetin supplementation is effective in improving mitochondrial dysfunctions induced by 3 nitropropionic acid: Implications in Huntington's disease. Biochim Biophys Acta - Mol Basis Dis 1832:421-430. doi: 
10.1016/j.bbadis.2012.11.018

30. Sroka Z, Sowa A, Dryś A (2017) Inhibition of lipoxygenase and peroxidase reaction by some flavonols and flavones: The structure-activity relationship. Nat Prod Commun 12:1705-1708. doi: $10.1177 / 1934578 \times 1701201111$

31. Subramanian $P$, Mendez EF, Becerra SP (2016) A Novel Inhibitor of 5Lipoxygenase (5-LOX) Prevents Oxidative Stress-Induced Cell Death of Retinal Pigment Epithelium (RPE) Cells. Investig Opthalmology Vis Sci 57:4581. doi: 10.1167/iovs.15-19039

32. Umar AK (2021) Flavonoid compounds of buah merah (Pandanus conoideus Lamk) as a potent SARSCoV-2 main protease inhibitor: in silico approach. Futur J Pharm Sci 7:08. doi: 10.1186/s43094-021-00309-0

33. Vafadar A, Shabaninejad Z, Movahedpour A, Fallahi F, Taghavipour M, Ghasemi Y, Akbari M, Shafiee A, Hajighadimi S, Moradizarmehri S, Razi E, Savardashtaki A, Mirzaei H (2020) Quercetin and cancer: new insights into its therapeutic effects on ovarian cancer cells. Cell Biosci 10:32. doi: 10.1186/s13578-020-00397-0

34. Wang Y, Branicky R, Noë A, Hekimi $S$ (2018) Superoxide dismutases: Dual roles in controlling ROS damage and regulating ROS signaling. J Cell Biol 217:1915-1928. doi: 10.1083/jcb.201708007

35. Ward AB, Mir H, Kapur N, Gales DN, Carriere PP, Singh S (2018) Quercetin inhibits prostate cancer by attenuating cell survival and inhibiting antiapoptotic pathways. World J Surg Oncol 16:108. doi: 10.1186/s12957018-1400-z

36. Weinberg F, Chandel NS (2009) Reactive oxygen species-dependent signaling regulates cancer. Cell Mol Life Sci 66:3663-3673. doi: 10.1007/s00018-009-0099-y

37. $\mathrm{Xu} \mathrm{D,} \mathrm{Hu} \mathrm{MJ,} \mathrm{Wang} \mathrm{YQ,} \mathrm{Cui} \mathrm{YL}$ (2019) Antioxidant activities of quercetin and its complexes for medicinal application. Molecules 24. doi: 10.3390/molecules 24061123

38. Zhang Y, Wang D, Yang L, Zhou D, Zhang J (2014) Purification and Characterization of Flavonoids from the Leaves of Zanthoxylum bungeanum and Correlation between Their Structure and Antioxidant Activity. PLoS One 9:e105725. doi: 10.1371/journal.pone.0105725

39. Zheng Y-Z, Deng G, Liang Q, Chen DF, Guo R, Lai R-C (2017) Antioxidant Activity of Quercetin and Its Glucosides from Propolis: A Theoretical Study. Sci Rep 7:7543. doi: 10.1038/s41598-017-08024-8 